\title{
CREB transcription in the medial prefrontal cortex regulates the formation of long-term associative recognition memory
}

\author{
Gareth Robert Barker, ${ }^{1}$ Liang Fong Wong, ${ }^{2}$ James B. Uney, ${ }^{2}$ and Elizabeth C. Warburton ${ }^{1}$ \\ ${ }^{1}$ School of Physiology, Pharmacology and Neuroscience, University of Bristol, Bristol BS8 1 TD, United Kingdom; ${ }^{2}$ School of Translational \\ Health Sciences, University of Bristol, Bristol BS8 1TD, United Kingdom
}

\begin{abstract}
The medial prefrontal cortex (mPFC) is known to be critical for specific forms of long-term recognition memory, however the cellular mechanisms in the mPFC that underpin memory maintenance have not been well characterized. This study examined the importance of phosphorylation of cAMP responsive element binding protein (CREB) in the mPFC for different forms of long-term recognition memory in the rat. Adenoviral transduction of the $\mathrm{MPFC}$ with a dominant-negative inhibitor of CREB impaired object-in-place memory following a 6 or $24 \mathrm{~h}$ retention delay, but no impairment was observed following delays of $5 \mathrm{~min}$ or $3 \mathrm{~h}$. Long-term object temporal order memory and spatial temporal order memory was also impaired. In contrast, there were no impairments in novel object recognition or object location memory. These results establish, for the first time, the importance of CREB phosphorylation within the mPFC for memory of associative and temporal information crucial to recognition.
\end{abstract}

Neural activity within the frontal lobes is crucial for declarative memory processing. Patients with lesions in the prefrontal cortex (PFC) show impairments in both episodic memory (Rugg and Vilberg 2013) and in the recognition of stimuli associated with specific spatial and temporal information (Kopelman et al. 1997; Zhang et al. 2018) and fMRI studies have revealed activation in PFC subregions during associative recognition and temporal order memory (Dobbins et al. 2003; St Jacques et al. 2008; Park et al. 2012; Roberts et al. 2018). More selective recording and lesion studies in nonhuman primates and rodents, have demonstrated a role for the orbital or medial PFC (mPFC) in delayed matching to sample, object-in-place recognition memory and temporal order memory (Mitchell and Laiacona 1998; Hannesson et al. 2004a,b; Browning et al. 2005; Johnston and Everling 2006; Barker et al. 2007; Baxter et al. 2007; Barker and Warburton 2011a). Thus, across species evidence strongly points to an involvement of the $\mathrm{mPFC}$ in associative and recency memory.

In the rat in vivo electrophysiological recording studies have revealed populations of neurons in the $\mathrm{MPFC}$, which display object and context-dependent modulation (Kim et al. 2011, 2013, 2018; Hyman et al. 2012; Weible et al. 2012). Such firing patterns may thus represent a cellular mechanism for recognition memory involving spatio-temporal information, although these mechanisms have been reported to operate over relatively short timescales. The intracellular mechanisms that support the formation and longterm storage of such memories in the mPFC have been little investigated, perhaps in part because traditionally the PFC has been associated with short-term memory processing (Baddeley 1992).

For long-term memory formation, phosphorylation of the transcription factor cAMP responsive element binding protein (CREB) has been shown to be a critical step in other brain regions. Inactivation of CREB in the hippocampus has been shown to impair contextual fear and spatial memory (Silva et al. 1998; Kida et al. 2002), in the perirhinal cortex CREB inactivation impaired long-term object recognition memory (Warburton et al. 2005)

\section{Corresponding author: e.c.warburton@bristol.ac.uk}

Article is online at http://www.learnmem.org/cgi/doi/10.1101//m.050021.119. and in the MPFC disruption of CREB signaling impaired objectlocation memory in a delay-dependent manner (Vieira and Korzus 2015). Enhancement of CREB function in the amygdala has been shown to improve fear memory (Josselyn et al. 2001) and expression of CREB binding protein has been shown to increase in the mPFC following fear learning (Siddiqui et al. 2017). Thus, CREB activation in the mPFC may be a key step in the maintenance of object recognition memory yet this hypothesis has not yet been tested.

Here we investigated the effect of blocking CREB phosphorylation in the mPFC on the formation of object-in-place, temporal order and temporal location associative recognition memory using a virus expressing a dominant-negative inhibitor of CREB (here denoted A-CREB). The A-CREB construct consists of an acidic amphipathic extension that replaces the natural basic region fused on to the amino terminus of the CREB leucine domain. The acidic extension interacts with the basic region of endogenous CREB-forming a coiled-coil extension of the leucine zipper and preventing CREB from binding DNA and initiating CRE-mediated transcription. We have previously used this approach to investigate the importance of CREB phosphorylation to recognition memory formation in the perirhinal cortex region of the medial temporal lobe (Warburton et al. 2005).

\section{Results}

Histology

Both control and A-CREB adenoviral vectors were tagged with enhanced green fluorescent protein (EGFP) for visualization. Infusion of the vectors produced localized transgene expression, in all animals, centered in the prelimbic/infralimbic (PL/IL) region of

2020 Barker et al. This article is distributed exclusively by Cold Spring Harbor Laboratory Press for the first 12 months after the full-issue publication date (see http://learnmem.cshlp.org/site/misc/terms.xhtml). After 12 months, it is available under a Creative Commons License (AttributionNonCommercial 4.0 International), as described at http://creativecommons. org/licenses/by-nc/4.0/. 
$\mathrm{mPFC}$ at the injection site, $+3.2 \mathrm{~mm}$ AP from bregma (Fig. 1F). Expression was observed up to $0.5 \mathrm{~mm}$ from the injection site both in the anterior and posterior direction and throughout the dorsal-ventral extent of PL and IL, although expression was restricted to a $150 \mu \mathrm{M}$ width in the mediolateral direction. Transgene expression was observed in the anterior cingulate cortex particularly in that region adjacent to PL but only at the injection site. There was minimal tissue damage as assessed by cresyl violet staining.

\section{Disruption of CREB phosphorylation impairs long term object-in-place memory formation}

To examine the effects of CREB-disruption in the mPFC on object-in-place memory, we injected one group of rats with the vi- rus expressing a dominant negative inhibitor of CREB (A-CREB group) while a second group of rats received a virus expressing EGFP only (EGFP group) as a control group. In the sample phase of the object-in-place the subject was placed in the arena to explore four different objects (Fig. 1A). After a delay period, the rat was replaced in the arena, which contained the four same objects, but two of the objects had exchanged position Discrimination between two objects which had exchanged position and the two objects which were in the same position (Fig. 1A) was calculated using a discrimination ratio (DR) which controlled for individual differences in exploration levels. Object-in-place memory performance was assessed after four different retention delays (5 $\mathrm{min}, 3,6$, and $24 \mathrm{~h}$ ) in four separate runs. Consistent with our previous studies it was predicted that control animals will spend more time exploring the moved objects

A

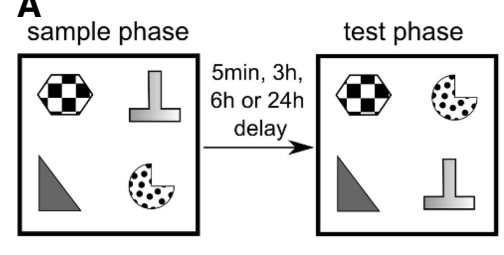

B

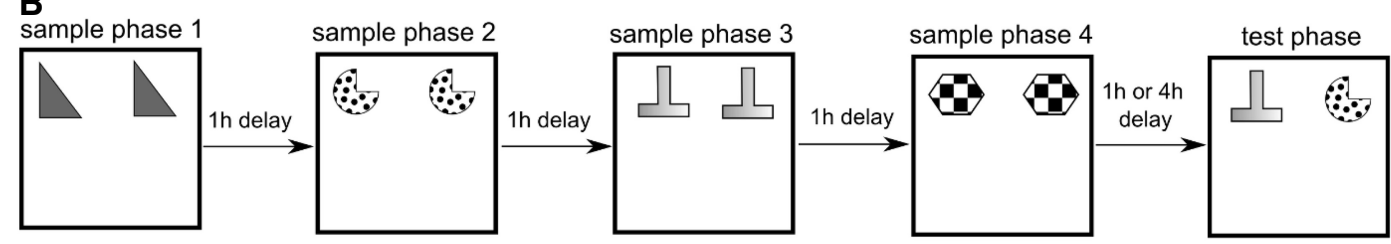

C

sample phase 1

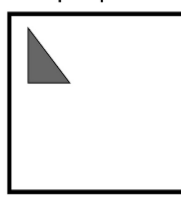

D

sample phase

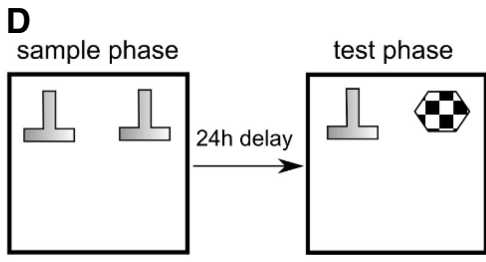

sample phase 2

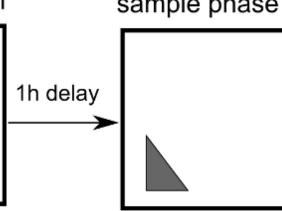

test phase

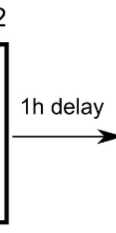

sample phase 3

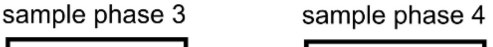

sample phase 4

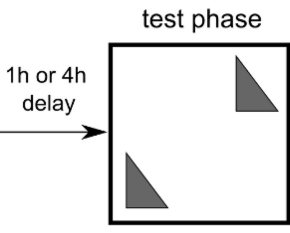

E

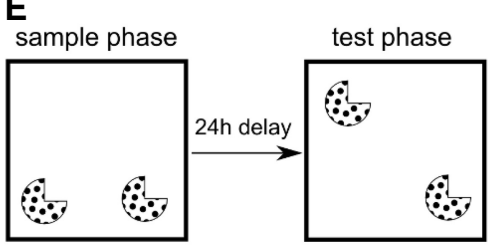

F

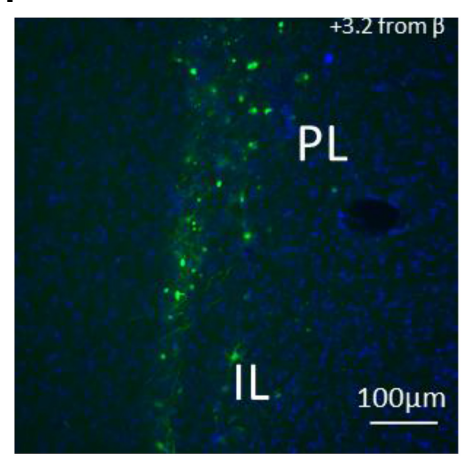

Figure 1. Diagram of the spontaneous object recognition tasks used: $(A)$ Object-in-place task, $(B)$ object temporal order task, $(C)$ object temporal location task, $(D)$ object recognition task, $(E)$ object location task, $(F)$ EGFP expression in the prelimbic (PL) and infralimbic (IL) region of the mPFC after infusion of adenoviral vector. Image taken at +3.2 from bregma $(\beta)$. 
Table 1. Total object exploration times during the sample and test phases of the object in place task

\begin{tabular}{llcc} 
Delay & Condition & $\begin{array}{c}\text { Exploration in sample } \\
\text { phase (s) }\end{array}$ & $\begin{array}{c}\text { Exploration in test } \\
\text { phase (s) }\end{array}$ \\
\hline $5 \mathrm{~min}$ & EGFP & $86.3 \pm 6.5$ & $32.0 \pm 3.77$ \\
& A-CREB & $100.1 \pm 4.2$ & $33.6 \pm 3.1$ \\
$\mathrm{~h}$ & EGFP & $73.3 \pm 7.6$ & $35.4 \pm 2.5$ \\
& A-CREB & $81.5 \pm 5.0$ & $39.0 \pm 2.2$ \\
$6 \mathrm{~h}$ & EGFP & $66.3 \pm 4.3$ & $29.5 \pm 4.2$ \\
& A-CREB & $79.7 \pm 3.8$ & $38.5 \pm 1.9$ \\
$24 \mathrm{~h}$ & EGFP & $88.7 \pm 5.9$ & $40.0 \pm 3.2$ \\
& A-CREB & $103.3 \pm 4.7$ & $47.2 \pm 3.6$ \\
\hline
\end{tabular}

Data presented as mean $\pm \operatorname{SEM}(n=10)$.

compared to the unmoved objects across each delay, and thus demonstrate memory for both the objects and the places in which they were previously encountered.

As overall object exploration levels could have an effect on memory encoding, we examined such exploration during different stages of the task and found no differences during the sample phase between the A-CREB and EGFP groups in any of the delay conditions [delay $\times$ virus interaction $F_{(3,72)}=0.12, P=0.95$ ]. Similarly, there were no differences in total object exploration during the test phase in any of the delay conditions [delay $x$ virus interaction $\left.F_{(3,72)}=0.29, P=0.83\right]$. The mean sample and test phase exploration for each condition at each delay is shown in Table 1.

Figure 2A shows the mean DR for the EGFP and A-CREB groups at each retention delay and it can be seen that object-in-place memory was impaired in the A-CREB group at the longer ( 6 and $24 \mathrm{~h}$ ) but not at the shorter retention delays ( $5 \mathrm{~min}, 3 \mathrm{~h}$ ) while performance in the EGFP group was unimpaired at any of the delays tested. Statistical analyses revealed a significant delay $\times$ virus interaction $\left[F_{(3,72)}=10.36, P=0.0001\right]$ and post-hoc analyses showed a significant difference between the memory performance of the A-CREB and EGFP rats at the longer delays (6 h $P=0.0001 ; 24 \mathrm{~h} P=0.0001$ ) but not at the shorter delays (5 min $P=0.650 ; 3$ h $P=0.702$ ).

\section{Disruption of CREB phosphorylation impairs long term temporal order memory formation}

We next examined performance in a temporal order memory task in which the subjects were presented with objects in a sequence of four sample phases (S1-S4). In the test phase, the objects from S2 and S3, were presented and exploration of these objects measured. Memory for order was expressed by the preferential exploration of the object which had occurred earlier in the series that is, object from S2 (Fig. 1B). Memory performance was calculated as a DR.

The A-CREB and EGFP groups showed the same levels of object exploration during each of the four sample phases [sample phase $\times$ virus $\times$ delay interaction $F_{(3,108)}=1.20, P=0.31$ n.s.] and in the test phase [delay by virus interaction $F_{(1,36)}=0.87, P=0.36$ n.s.]. The mean sample and test phase exploration at each delay is shown in Table 2 .

Figure $2 \mathrm{~B}$ shows the mean DR for the EGFP and A-CREB groups following either 3 or $6 \mathrm{~h}$ retention delay. Discrimination was significantly lower in the A-CREB compared to the EGFP group at the longer delay only [delay $\times$ virus interaction $F_{(1,36)}=4.33, P=$ 0.045 ] confirmed by post-hoc analyses showing a significant difference between the EGFP and A-CREB groups at the $6 \mathrm{~h}$ delay $(P=$ $0.006)$ but not at the $3 \mathrm{~h}$ delay $(P=0.92)$.
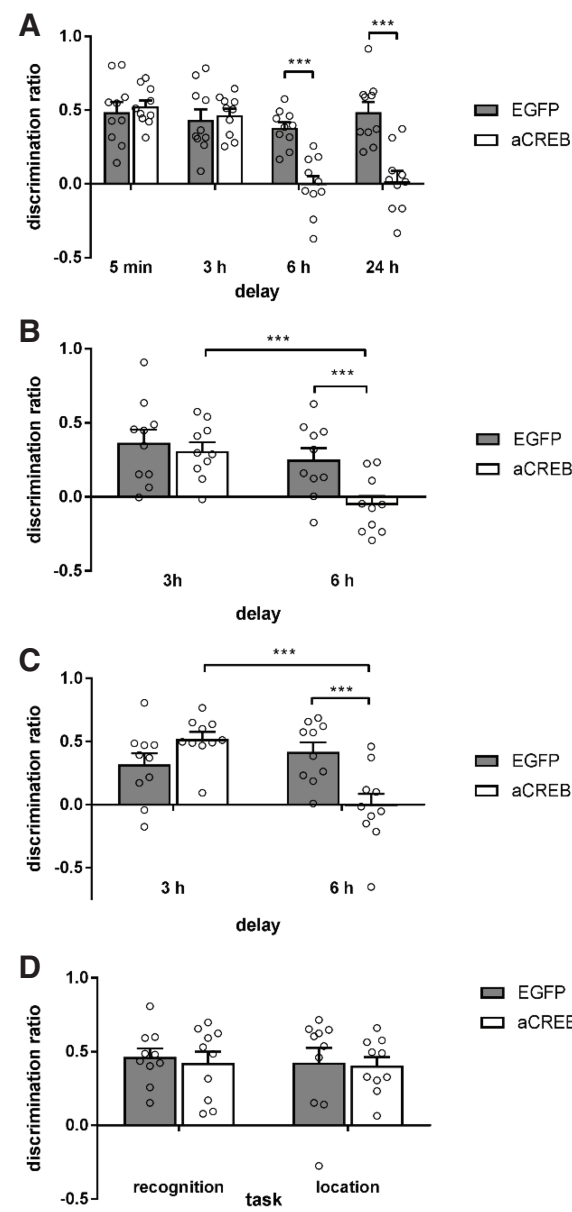

$\square$ EGFP

口 aCREB

Figure 2. Blockade of CREB function in the medial prefrontal cortex (mPFC) impaired long-term but not short-term associative recognition memory formation and did not alter long-term nonassociative recognition memory formation. $(A)$ Blockade of CREB function in the MPFC impaired long-term, but not short-term object-in-place memory. T-tests comparing the DRs of each group against chance performance revealed that at the 5 min and 3 h delays, both the EGFP and A-CREB groups showed significant object-in-place discrimination [5 min EGFP $t_{(9)}=7.08, P=0.0001, A-C R E B$ $t_{(9)}=12.95, P=0.0001 ; 3 \mathrm{~h}$ EGFP $t_{(9)}=6.11, P=0.0001$, A-CREB $t_{(9)}=$ $10.87, P=0.0001]$. In contrast at the 6 and $24 \mathrm{~h}$ delay the EGFP group showed significant discrimination $\left[6 \mathrm{~h} t_{(9)} 9.50, P=0.0001 ; 24 \mathrm{~h} t_{(9)}=\right.$ $7.131, P=0.0001]$ whereas the A-CREB group did not $\left[6 \mathrm{~h} t_{(9)}=-0.13 P=\right.$ $\left.0.899 ; 24 \mathrm{~h} t_{(9)}=0.30, P=0.77\right]$. (B) Blockade of CREB function in the mPFC impaired long-term, but not short-term temporal order memory. $T$-tests comparing the DRs of each group against chance performance revealed that at the $3 \mathrm{~h}$ delay both the EGFP and A-CREB groups showed significant discrimination between the object presented in S2 and S3 [EGFP $t_{(9)}=4.09, P=0.003$; A-CREB $t_{(9)}=5.25, P=0.001$ ]. At the 6 h delay the EGFP group showed significant discrimination $\left[t_{(9)}=3.27, P=0.010\right]$ while the A-CREB did not show significant discrimination $\left[t_{(9)}=-0.91, P=\right.$ 0.385]. (C) Blockade of CREB function in the mPFC impaired long-term, but not short-term temporal location memory. T-tests comparing the DRs of each group against chance performance revealed that at the $3 \mathrm{~h}$ delay both the EGFP and A-CREB groups showed significant discrimination between the object presented in S2 and S3 [EGFP $t_{(9)}=3.54, P=0.006$; A-CREB $\left.t_{(9)}=9.24, P=0.000\right]$. At the $6 \mathrm{~h}$ delay the EGFP group showed significant discrimination $\left[t_{(9)}=5.62, P=0.000\right]$ while the A-CREB did not show significant discrimination $\left[t_{(9)}=-0.12, P=0.91\right]$. (D) Blockade of CREB function in the MPFC had no effect on novel object recognition or object location memory. $T$-tests comparing the DRs against chance performance revealed that all groups showed significant discrimination between the novel and familiar objects in the object recognition task [EGFP $t_{(9)}=$ 8.060, $P=0.000$; A-CREB $\left.t_{(9)}=5.61, P=0.000\right]$. Both groups also showed significant discrimination between the moved and unmoved objects in the object location task [EGFP $t_{(9)}=4.23, P=0.002$; A-CREB $t_{(9)}=7.00, P=$ $0.000]$. Data presented as mean \pm SEM. $\left({ }^{* * *}\right) P<0.001$. 
mPFC CREB crucial for long-term recognition memory

Table 2. Total object exploration completed in the sample phases and the test phases of the object temporal order and the temporal location tasks

\begin{tabular}{|c|c|c|c|c|c|c|c|}
\hline \multirow[b]{2}{*}{ Task } & \multirow[b]{2}{*}{ Delay } & \multirow[b]{2}{*}{ Condition } & \multicolumn{4}{|c|}{ Exploration in sample phase (s) } & \multirow[b]{2}{*}{ Exploration in test phase (s) } \\
\hline & & & S1 & S2 & S3 & S4 & \\
\hline Object temporal order & $\begin{array}{l}3 \mathrm{~h} \\
6 \mathrm{~h}\end{array}$ & $\begin{array}{l}\text { EGFP } \\
\text { A-CREB } \\
\text { EGFP } \\
\text { A-CREB }\end{array}$ & $\begin{array}{l}50.4 \pm 4.0 \\
54.4 \pm 4.7 \\
55.0 \pm 5.8 \\
56.8 \pm 3.8\end{array}$ & $\begin{array}{l}55.1 \pm 5.3 \\
57.5 \pm 4.8 \\
51.1 \pm 6.4 \\
41.4 \pm 6.0\end{array}$ & $\begin{array}{l}61.6 \pm 5.4 \\
45.3 \pm 4.4 \\
40.1 \pm 4.3 \\
34.5 \pm 5.8\end{array}$ & $\begin{array}{l}35.5 \pm 4.4 \\
48.0 \pm 5.3 \\
46.1 \pm 6.5 \\
49.3 \pm 5.4\end{array}$ & $\begin{array}{l}37.0 \pm 3.3 \\
38.0 \pm 3.7 \\
34.9 \pm 5.1 \\
28.4 \pm 2.6\end{array}$ \\
\hline Temporal location & $\begin{array}{l}3 \mathrm{~h} \\
6 \mathrm{~h}\end{array}$ & $\begin{array}{l}\text { EGFP } \\
\text { A-CREB } \\
\text { EGFP } \\
\text { A-CREB }\end{array}$ & $\begin{array}{l}43.2 \pm 5.1 \\
41.1 \pm 5.4 \\
23.4 \pm 2.6 \\
29.2 \pm 2.0\end{array}$ & $\begin{array}{l}43.3 \pm 3.5 \\
52.9 \pm 2.8 \\
29.8 \pm 3.3 \\
26.8 \pm 6.7\end{array}$ & $\begin{array}{l}46.5 \pm 6.5 \\
49.9 \pm 5.6 \\
38.0 \pm 4.7 \\
39.0 \pm 8.6\end{array}$ & $\begin{array}{l}43.4 \pm 3.4 \\
42.9 \pm 5.7 \\
34.4 \pm 2.2 \\
32.5 \pm 3.4\end{array}$ & $\begin{array}{l}24.2 \pm 2.4 \\
26.8 \pm 4.5 \\
27.3 \pm 2.6 \\
27.4 \pm 2.5\end{array}$ \\
\hline
\end{tabular}

Data presented as mean $\pm \operatorname{SEM}(n=10)$.

\section{Disruption of CREB phosphorylation impairs object temporal location}

Activity within the mPFC is required for object associative and object temporal memory performance, thus we next examined the requirement for CREB activity in the MPFC for object temporal location memory. Here, the animal was presented with the same object but in a sequence of four different locations across four sample phases (Fig. 1C). In the test phase, the animal was presented with two objects, one in location from S2, one in location S3. Intact memory for the order of locations was expressed by preferential exploration of the object in the location that appeared earlier in the list (i.e., S2). Again, memory performance was assessed using the DR.

Both the A-CREB and EGFP groups completed the same amount of exploration in each of the sample phases and between the sample phases [sample phase $\times$ virus $\times$ delay interaction $F_{(3,108)}$ $=1.12, P=0.35]$. There was also no difference in object exploration between the groups in the test phase [delay $\times$ virus interaction $\left.F_{(1,36)}=0.15, P=0.70\right]$. The mean sample and test phase exploration at each delay is shown in Table 2 .

Figure 2C shows the mean DR for the EGFP and A-CREB groups following either the 3 or $6 \mathrm{~h}$ delay. Statistical analysis revealed a significant delay by virus interaction $\left[F_{(1,36)}=15.14, P=\right.$ 0.000 ] and post-hoc analyses showed that memory performance in the A-CREB group was significantly reduced compared to control at the $6 \mathrm{~h}$ retention delay $(P=0.003)$ but there was no difference between the groups at the $3 \mathrm{~h}$ delay $(P=0.071)$.

\section{Disruption of CREB phosphorylation in the $\mathrm{mPFC}$ has no effect on novel object recognition or object location memory}

To establish the selectivity of the mnemonic effects of CREB disruption in the $\mathrm{MPFC}$, we tested the A-CREB and EGFP groups in a novel object recognition task (Fig. 1D), and an object location task (Fig. 1E), both tasks previously shown to be unaffected by mPFC ablation (Barker et al. 2007). In novel object recognition task, the animals are presented with two identical objects and in the test phase, one of the objects is replaced with a novel object. In the object location task, the animals explore two identical objects in the sample phase, and in the test phase one of the objects is moved to a new location. Intact memory is expressed by preferential exploration of the novel or moved object.

The A-CREB and EGFP groups completed the same amount of object exploration during the sample phase $\left[F_{(1,18)}=3.396, P=\right.$ $0.082]$ and test phase $\left[F_{(1,18)}=0.80, P=0.38\right]$ of the novel object recognition test. Statistical analysis of memory performance revealed a nonsignificant main effect of virus $\left[F_{(1,18)}=0.174, P=0.68\right]$ thus there was no effect of blocking CREB function in the PFC on novel object recognition (Fig. 2D). In the object location task there was a difference in the amount of object exploration in the sample phase $\left[F_{(1,18)}=6.038, P=0.024\right]$ and inspection of the group means revealed that this difference was a result of greater sample phase exploration in the A-CREB group compared to the EGFP group. There was no difference in object exploration in the test phase $\left[F_{(1,18)}=\right.$ $2.659, P=0.12]$ and no difference in memory performance $\left[F_{(1,18)}\right.$ $=0.34, P=0.86]$ (Fig. 2D), hence there was no effect of blocking CREB function in the $\mathrm{mPFC}$ on object location memory. The sample and test phase exploration during each task is shown in Table 3.

\section{Discussion}

CREB activity is a key regulator in the formation of long-term memory and here we show that selective disruption of CREB phosphorylation in the $\mathrm{mPFC}$, impaired long-term object-in-place associative recognition memory, object temporal order memory, and spatial temporal order memory. In contrast, there were no impairments in novel object recognition or object location memory, further there was no effect on performance at the shortest retention delays tested (i.e., $5 \mathrm{~min}$ or $3 \mathrm{~h}$ ). Finally, there were no changes in the animals' overall object exploration behavior during either the sample or test phases. Together these results show that the deficits in recognition performance were not a result of a general attentional or motor deficits, but rather that disruption of CREB function in the mPFC specifically impaired long-term associative memory performance.

Table 3. Total object exploration completed in the sample and test phases of the object recognition and object location tasks

\begin{tabular}{llccc}
\hline Task & Condition & Time taken to complete sample phase (s) & Exploration in sample phase (s) & Exploration in test phase (s) \\
\hline Object recognition & EGFP & $162.8 \pm 23.1$ & $36.5 \pm 1.5$ & $29.8 \pm 2.6$ \\
Object location & A-CREB & $153.4 \pm 19.6$ & $39.4 \pm 0.3$ & $32.8 \pm 1.6$ \\
& EGFP & n/a & $45.1 \pm 2.9$ & $30.1 \pm 1.9$ \\
& A-CREB & n/a & $54.6 \pm 2.2$ & $35.0 \pm 2.2$ \\
\hline
\end{tabular}

Data presented as mean $\pm \operatorname{SEM}(n=10)$. 
We have previously established the cellular and behavioral functionality of the adenoviral mediated dominant-negative construct A-CREB used in this study. Thus Warburton et al. (2005) reported that expression of A-CREB selectively in the perirhinal cortex produced a $40 \%$ reduction in overall pCREB levels, and impaired long-term ( $24 \mathrm{~h}$ delay), but not short-term (15 min) single item novel object recognition memory. Here histological analysis revealed transgene expression restricted along the dorsoventral extent of the prelimbic and infralimbic cortex of the mPFC, with only minimal expression in the anterior cingulate cortex.

Previous studies have shown that the $\mathrm{MPFC}$ is not required for familiarity discrimination or simple spatial tasks (Hannesson et al. 2004b; Barker et al. 2007, but see Vieira and Korzus, 2015) likewise here disruption of CREB activity in the mPFC did not affect novel object recognition or object location. Significantly the present study found deficits in object-in-place memory following both a 6 and $24 \mathrm{~h}$ retention delay, but not at $5 \mathrm{~min}$ or $3 \mathrm{~h}$. A retention delay of $6 \mathrm{~h}$ is much shorter than had been investigated in previous studies (Bourtchuladze et al. 1994; Guzowski and McGaugh 1997; Peters et al. 2009), and the deficit at this timepoint indicates that CREB phosphorylation is an important step in a cellular pathway for the stabilization of memory information between 3 and $6 \mathrm{~h}$ following learning. From our previous studies initiation of this cellular pathway appears to depend on the activation of specific receptor subtypes in the mPFC such as the NMDA and D1/D5 receptor and blockade of these receptors impairs both object-in-place (Barker and Warburton 2008, 2011b; Savalli et al. 2015), and temporal order memory (Hotte et al. 2006) and interestingly activation of the NMDA and D1/D5 receptors has been shown to be crucial for CREB phosphorylation (Pittenger et al. 2002; Hotte et al. 2006; Olianas et al. 2012; Kirschmann et al. 2014; Nygard et al. 2017). CREB expression is regulated at transcriptional level by epigenetic mechanisms such as DNA methylation (Chahrour et al. 2008) and we have shown that disruption of DNA methylation impairs longterm object-in-place memory (Chahrour et al. 2008; Scott et al. 2017). Hence there are direct links between receptor activation, CREB-mediated cellular processes and gene expression in the $\mathrm{mPFC}$, that leads to the long-term associative and temporal order recognition memory formation.

Previous studies have demonstrated that the PFC plays an important role in sequence behaviors specifically within the context of short-term memory, where delay-period activity in the PFC has been reported to represent temporal order, as well as a number of other variables (Funahashi 2017; Naya et al. 2017). Here temporal order memory for objects or locations was demonstrated by preferential exploration of the object in the location encountered earlier in the sequence. There are at least two possible mechanisms that may drive discrimination; either recency/ memory strength that is, animals have weaker memory for the "older" information that is, that encoded during sample phase 2 compared to sample phase 3 , or the animals remember the order of locations encountered. While some have argued that memory strength or trace decay drives the behavior (Staddon and Higa 1999) recent data from our laboratory shows that manipulations of the length of the inter-sample interval, which should disproportionately affect memory strength compared to memory for order, have little effect on performance (Barker et al. 2019). Hence, we would suggest that animals are making order judgements, at least in part, independent of memory strength, although the latter cannot be completely excluded. It should also be considered that while neural activity in the $\mathrm{mPFC}$ is crucial for maintenance of information to guide behavior (for review, see Miller et al. 2018) processing of multiple stimuli as is required for temporal order memory, will be vulnerable to interference due to its limited capacity. Here four objects or positions were used and order memory for the middle items examined to avoid primary and recency effects associated with the first and last items, thus we did not explore the impact of manipulation of PFC processing on different order effects in the present study. Alternatively, the mPFC may play a more general role in integration and discrimination of information encoded within overlapping representations, possibly via an interaction with the hippocampus (DeVito et al. 2010; Schlichting and Preston 2015; Morton et al. 2017). Indeed, successful object-in-place and object and spatial temporal order memory require prefrontalhippocampal interactions (Barker and Warburton 2011a; Barker et al. 2017).

In conclusion selective disruption of CREB phosphorylation within the mPFC impaired object-in-place, temporal order and temporal location memory, following delays greater than $6 \mathrm{~h}$. This finding suggests the existence of a common intracellular CREB-dependent mechanism for long-term recognition memory formation of associative and temporal information. The cellular processes of memory stabilization in the mPFC parallel those in other regions of the cortex that is, the perirhinal cortex that have been shown to be required for single item object recognition memory. However, the precise molecular pathway has yet to be established. Further work is now required to define the precise interactions that comprise the molecular networks within PFC neurons, and the nature of the memory information consolidated within the mPFC.

\section{Materials and Methods}

\section{Subjects}

All experiments were conducted in male Lister hooded rats (Harlan Laboratories) weighing 300-350 g at the start of the experiments. The animals were group housed, under a 12-h/12-h light-dark cycle (light phase 18:00-6:00 h). Behavioral training and testing were conducted during the dark phase of the cycle. Food and water were available ad libitum throughout the experiment. All animal procedures were performed in accordance with United Kingdom Animals Scientific Procedures Act (1986) and associated guidelines. All efforts were made to minimize any suffering and the number of animals used.

\section{Adenoviral preparation}

Recombinant E1-deleted Ad constructs were produced according to standard techniques (Harding et al. 1998). The cDNA for the reporter contrast enhanced green-fluorescent protein (EGFP), was excised from pEGFP1 (Clontech) using HindIII and XbaI and inserted into the corresponding site in the multiple cloning site of the plasmid pXCXCMV (Harding et al. 1998). The cDNAs for CREB and the dominant-negative A-CREB were expressed bicistronically with EGFP by cloning each individually onto the same Ad transfer plasmid. Recombinant virus was generated by homologous recombination in human embryonic kidney 293 cells (Microbix Biosystems), grown to a high titer and purified by $\mathrm{CsCl}$ density gradient centrifugation. Viral titer was determined by plaque assay: Ad-CMV-EGFP was $1 \times 10^{10} \mathrm{pfu} / \mathrm{mL}$, and Ad-CMV-A-CREB was $1 \times$ $10^{10} \mathrm{pfu} / \mathrm{mL}$.

\section{Surgery}

Each rat was anaesthetized with isoflurane (induction 4\%, maintenance $2 \%-3 \%$ ) and secured in a stereotaxic frame with the incisor bar set at $-3.5 \mathrm{~mm}$ below the interaural line, in order to obtain flat skull. The scalp was then cut and retracted to expose the skull. Craniotomies were then made directly above the target regions, and the dura cut to expose the cortex.

Viral particles were delivered bilaterally into the mPFC (AP + $3.2 \mathrm{~mm}$; ML $\pm 0.5 \mathrm{~mm}, \mathrm{DV}-4.3 \mathrm{~mm}$ ) in $2.0 \mu \mathrm{L}$ per hemisphere at a rate of $200 \mathrm{~nL} / \mathrm{min}$. Animals were allowed to recover for $3 \mathrm{wk}$ before behavioral testing commenced. 


\section{Histology}

Following completion of the experiments, each rat was anaesthetized with Euthetal (Rhône Mérieux) and perfused transcardially with phosphate-buffered saline followed by $4 \%$ paraformaldehyde. After removal the brain was post-fixed in paraformaldehyde for $24 \mathrm{~h}$ before being transferred to $30 \%$ sucrose in $0.2 \mathrm{M}$ phosphate buffer for $48 \mathrm{~h}$. Coronal sections were cut at $40 \mu \mathrm{m}$ on a cryostat. Alternate sections were Nissl stained with cresyl violet or mounted directly onto slide using Vectorshield (Vector Laboratories) coverslipped and examined using a fluorescent microscope (Leica DM6 B).

\section{Behavioral Protocols (Fig. 1A-E)}

Object exploration occurred in a wooden open topped arena $90 \times$ $100 \mathrm{~cm}$ with walls $50 \mathrm{~cm}$ high. Object exploration was video recorded for subsequent analysis. The stimuli presented were objects composed of Duplo blocks (Lego UK Ltd) that varied in shape, color and size $(9 \times 8 \times 7 \mathrm{~cm}$ to $25 \times 15 \times 10 \mathrm{~cm})$ and were too heavy for the animal to displace.

Habituation was conducted over $4 \mathrm{~d}$ prior to the commencement of behavioral testing. On days one and two animals were habituated to the arena for 15 min with their cage mates, on days three and four, each animal was placed individually in the arena for $5 \mathrm{~min}$.

\section{Object-in-place memory}

This task comprised a sample and test phase, separated by delays of $5 \mathrm{~min}, 3$, 6, or $24 \mathrm{~h}$. Performance at each retention delay was examined in different experiments each with a sample and test phase using different quartets of objects. In each sample phase (5 min duration) the rats explored four different objects. In the test phase (3 min duration), two of the objects exchanged positions, see Figure $1 \mathrm{~A}$. The rats were tested at the different delay conditions in an interleaved manner with an interval of 3-7 d between experiments.

\section{Object temporal order memory}

This task comprised four sample phases (S1-S4) separated by a 1-h inter-sample interval (ISI) in which different objects were presented. During the sample phases (4 min duration each) the rats were presented with two copies of the object for $4 \mathrm{~min}$. The test phase occurred either 1 or $4 \mathrm{~h}$ following S4, to give a retention delay between S2 and test phase of either 3 or $6 \mathrm{~h}$. In the test phase ( $3 \mathrm{~min}$ duration) the rats were presented with objects from S2 and S3, see Figure 1B.

\section{Object temporal location memory}

This task involved four sample phases (S1-S4) separated by a $1 \mathrm{~h}$ ISI. In each 4 min sample phase, the rats encountered one object, the position of which changed. The test phase (3 min duration) occurred either 1 or $4 \mathrm{~h}$ following the end of S4, as in the temporal order task. In the test phase the rats were presented with two objects, one in the S2 location and the other in the S3 location, see Figure 1C.

\section{Novel object recognition memory}

In the sample phase ( 4 min duration) the rat explored two identical objects. In the test phase ( 3 min duration), $24 \mathrm{~h}$ later, rats were placed back in the arena, which now contained the sample phase object and a novel object, see Figure 1D.

\section{Object location memory}

In the sample phase (4 min duration) the rat explored two identical objects. In the test phase ( 3 min duration) conducted $24 \mathrm{~h}$ later the rat was placed back in the arena which contained the object from the sample phase in the same position as in the sample phase and an identical object was in a novel location, see Figure 1E.

\section{Assessment of object exploration and recognition memory performance}

The amount of time the animal spent exploring each object during the sample and test phases, during each task, was scored by the experimenter, blind to the animals' condition. Exploration was strictly defined as the animal directing its nose toward the object at a distance of $<2 \mathrm{~cm}$. From the time spent exploring the objects during the test phase, a DR was calculated to assess recognition memory. In the object-in-place memory task the DR was calculated from the difference in the time spent exploring the objects that had changed position compared to the objects that had remained in the same position. In the object temporal order memory and temporal location memory tasks the DR was calculated from a comparison of the time spent exploring the objects from S2 and S3. In the novel object recognition memory task, the DR was calculated from the difference in time spent exploring the novel compared to the familiar object(s) divided by the total time spent exploring all objects during the test phase. In the object location memory task, the DR was calculated from the difference in time spent exploring the moved and unmoved objects.

\section{Statistical analysis}

The sample size for each experiment was determined by previous studies conducted in both our and other laboratories. Power calculations on previously reported data (Barker et al. 2006; Barker and Warburton 2011a) collected in our laboratory suggest that to achieve a power of 0.8 , a group size of eight is required. Larger sample sizes were used to allow for maintenance of power should animals be excluded following histological analysis.

Memory performance between groups was compared using ANOVA analyses using SPSS (IBM). Statistical analyses were designed using an assumption of normal distribution and similar variance, but this was not formally tested. Performance in all the tasks used was compared using a two-way mixed design ANOVA with virus (EGFP or A-CREB) as the between subject factor and delay or sample phase (in the object temporal order or temporal location) as the within-subjects factor. Post-hoc tests used a Bonferroni correction for multiple comparisons. In addition to test whether each group of animals could significantly discriminate between objects or pairs of objects within each task, the DRs of each condition was compared to zero (chance performance) using a one-sample $t$-test (two-tailed).

\section{Acknowledgments}

This work was supported by a project grant from the Biotechnology and Biological Sciences Research Council (BB/100310X/1). We thank Jane Robbins for assistance with histology.

\section{References}

Baddeley A. 1992. Working memory. Science 255: 556-559. doi:10.1126/ science. 1736359

Barker GRI, Warburton EC. 2008. NMDA receptor plasticity in the perirhinal and prefrontal cortices is crucial for the acquisition of long-term object-in-place associative memory. J Neurosci 28: 2837-2844. doi:10 .1523/JNEUROSCI.4447-07.2008

Barker GRI, Warburton EC. 2011a. When is the hippocampus involved in recognition memory. J Neurosci 31: 10721-10731. doi:10.1523/ JNEUROSCI.6413-10.2011

Barker GRI, Warburton EC. 2011b. Evaluating the neural basis of temporal order memory for visual stimuli in the rat. Eur J Neurosci 33: 705-716. doi:10.1111/j.1460-9568.2010.07555.x

Barker GRI, Warburton EC, Koder T, Dolman NP, More JCA, Aggleton JP, Bashir ZI, Auberson YP, Jane DE, Brown MW. 2006. The different effects on recognition memory of perirhinal kainate and NMDA glutamate receptor antagonism: implications for underlying plasticity mechanisms. J Neurosci 26: 3561-3566.

Barker GRI, Bird F, Alexander V, Warburton EC. 2007. Memory for objects, place and temporal order: a disconnection analysis of the role of the medial prefrontal cortex and perirhinal cortex. J Neurosci 27: 29482957. doi:10.1523/JNEUROSCI.5289-06.2007 
Barker GRI, Banks PJ, Scott H, Ralph GS, Mitrophanous KA, Wong LF, Bashir ZI, Uney JB, Warburton EC. 2017. Separate elements of episodic memory subserved by distinct hippocampal-prefrontal connections. Nat Neurosci 20: 242-250. doi:10.1038/nn.4472

Barker GRI, Evuarherhe O, Warburton EC. 2019. Remembering the order of serially presented objects: a matter of time? Brain Neurosci Adv (in press). doi:10.1177/2398212819883088

Baxter MG, Gaffan D, Kyriazis DA, Mitchell AS. 2007. Orbital prefrontal cortex is required for object-in-place scene memory but not performance of a strategy implementation task. J Neurosci 27: 11327-11333. doi:10 $.1523 /$ JNEUROSCI.3369-07.2007

Bourtchuladze R, Frenguelli B, Blendy J, Cioffi D, Schutz G, Silva AJ. 1994. Deficient long-term memory in mice with a targeted mutation of the cAMP-responsive element-binding protein. Cell 7: 59-68. doi:10.1016/ 0092-8674(94)90400-6

Browning PG, Easton A, Buckley MJ, Gaffan D. 2005. The role of prefrontal cortex in object-in-place learning in monkeys. Eur J Neurosci 22: 32813291. doi:10.1111/j.1460-9568.2005.04477.x

Chahrour MJ, Jung SY, Shaw C, Zhou X, Wong ST, Qin J, Zoghbi HY. 2008. MeCP2, a key contributor to neurological disease, activates and represses transcription. Science 320: 1224-1229. doi:10.1126/science.1153252

DeVito LM, Lykken C, Kanter BR, Eichenbaum H. 2010. Prefrontal cortex: role in acquisition of overlapping associations and transitive inference. Learn Mem 17: 161-167. doi:10.1101/lm.1685710

Dobbins IG, Rice HJ, Wagner AD, Schacter DL. 2003. Memory orientation and success: separable neurocognitive components underlying episodic recognition. Neuropsychologia 41: 318-333. doi:10.1016/S0028-3932 (02)00164-1

Funahashi S. 2017. Working memory in the prefrontal cortex. Brain Sci 7: 49. doi:10.3390/brainsci7050049.

Guzowski JF, McGaugh JL. 1997. Antisense oligodeoxynucleotide-mediated disruption of hippocampal cAMP response element binding protein levels impairs consolidation of memory for water maze training. Proc Natl Acad Sci 94: 2693-2698. doi:10.1073/pnas.94.6.2693

Hannesson DK, Howland JG, Philips AG. 2004a. Interaction between perirhinal and medial prefrontal cortex is required for temporal order but not recognition memory for object in rats. J Neurosci 24: 4596-4604. doi:10.1523/JNEUROSCI.5517-03.2004

Hannesson DK, Vacca G, Howland JG, Philips AG. 2004b. Medial prefrontal cortex is involved in spatial temporal order memory but not spatial recognition memory in tests relying on spontaneous exploration in rats. Behav Brain Res 153: 273-285. doi:10.1016/j.bbr.2003.12.004

Harding TC, Geddes BJ, Murphy D, Knight D, Uney JB. 1998. Switching off transgene expression in the brain using an adenoviral tetracycline regulatable system. Nat Biotechnol 16: 553-555.

Hotte M, Thuault S, Lachaise F, Dineley KT, Hemmings HC, Nairn AC, Jay TM. 2006. D-1 receptor modulation of memory retrieval performance is associated with changes in PCREB and pDARPP-32 in rat prefrontal cortex. Behav Brain Res 171: 127-133. doi:10.1016/j.bbr.2006.03.026

Hyman JM, Ma L, Balaguer-Ballester E, Durstewitz D, Seamans JK. 2012. Contextual encoding by ensembles of medial prefrontal cortex neurons. Proc Natl Acad Sci 109: 5086-5091. doi:10.1073/pnas .1114415109

Johnston K, Everling S. 2006. Neural activity in monkey prefrontal cortex is modulated by task context and behavioral instruction during delayed-match-to-sample and conditional prosaccade-antisaccade tasks. J Cog Neurosci 18: 749-765. doi:10.1162/jocn.2006.18.5.749

Josselyn SA, Shi CJ, Carlezon WA, Neve RL, Nestler EJ, Davis M. 2001. Long-term memory is facilitated by cAMP response element-binding protein overexpression in the amygdala. J Neurosci 21: 2404-2412. doi:10.1523/JNEUROSCI.21-07-02404.2001

Kida S, Josselyn SA, Peña de Ortiz S, Kogan JH, Chevere I, Masushige S, Silva AJ. 2002. CREB required for the stability of new and reactivated fear memories. Nat Neurosci 5: 348-355. doi:10.1038/nn819

Kim JJ, Delcasso S, Lee I. 2011. Neural correlates of object-in-place learning in hippocampus and prefrontal cortex. J. Neurosci 47: 16991-17006. doi:10.1523/JNEUROSCI.2859-11.2011

Kim J, Ghim J-W, Lee JH, Jung MW. 2013. Neural correlates of interval timing in rodent prefrontal cortex. J. Neurosci 33: 13834-13847. doi:10 $.1523 /$ JNEUROSCI.1443-13.2013

Kim J, Kim D, Jung MW. 2018. Distinct dynamics of striatal and prefrontal neural activity during temporal discrimination. Front Integr Neurosci 12: 34. doi: $10.3389 /$ fnint. 2018.00034

Kirschmann EK, Mauna JC, Willis CM, Foster RL, Chipman AM, Thiels E. 2014. Appetitive cue-evoked ERK signaling in the nucleus accumbens requires NMDA and D1 dopamine receptor activation and regulates CREB phosphorylation. Learn Mem 21: 606-615. doi:10.1101/lm .035113 .114

Kopelman MD, Stanhope N, Kingsley D. 1997. Temporal and spatial context memory in patients with focal frontal, temporal lobe, and diencephalic lesions. Neuropsychologia 35: 1533-1545. doi:10.1016/S0028-3932(97) 00076-6
Miller EK, Lundqvist M, Bastos AM. 2018. Working Memory 2.0. Neuron 100: 463-475. doi:10.1016/j.neuron.2018.09.023

Mitchell JB, Laiacona J. 1998. The medial frontal cortex and temporal memory: tests using spontaneous exploratory behaviour in the rat. Behav Brain Res 97: 107-113. doi:10.1016/S0166-4328(98) 00032-1

Morton NW, Sherrill KR, Preston AR. 2017. Memory integration constructs maps of space time and concepts. Curr Opin Behav Sci 17: 161-168. doi:10.1016/j.cobeha.2017.08.007

Naya Y, Chen H, Yang C, Suzuki WA. 2017. Contributions of primate prefrontal cortex and medial temporal lobe to temporal-order memory. Proc Natl Acad Sci 114: 13555-13560.

Nygard SK, Klambatsen A, Balouch B, Quinones-Jenab V, Jenab S. 2017. NMDAR dependent intracellular responses associated with cocaine conditioned place preference behaviour. Behav Brain Res 317: 218-225. doi:10.1016/j.bbr.2016.09.047

Olianas MC, Dedoni S, Onali P. 2012. Potentiation of dopamine D1-like receptor signaling by concomitant activation of delta- and mu-opioid receptors in mouse medial prefrontal cortex. Neurochem Int 61: 1404-1416. doi:10.1016/j.neuint.2012.10.005

Park H, Shannon V, Biggan J, Spann C. 2012. Neural activity supporting the formation of associative memory versus source memory. Brain Res 1471: 81-92. doi:10.1016/j.brainres.2012.07.012

Peters M, Bletsch M, Catapano R, Zhang X, Tully Y, Bourtchouladze R. 2009. RNA interference in hippocampus demonstrates opposing roles for CREB and PP1 $\alpha$ in contextual and temporal long-term memory. Genes Brain Behav 8: 320-329. doi:10.1111/j.1601-183X.2009.00474.x

Pittenger C, Huang YY, Paletzki RF, Bourtchouladze R, Scanlin H, Vronskaya S, Kandel ER. 2002. Reversible inhibition of CREB/ATF transcription factors in region CA1 of the dorsal hippocampus disrupts hippocampus-dependent spatial memory. Neuron 34: 447-462. doi:10 .1016/S0896-6273(02)00684-0

Roberts BM, Libby LA, Inhoff MC, Ranganath C. 2018. Brain activity related to working memory for temporal order and object information. Behav Brain Res 354: 55-63. doi:10.1016/j.bbr.2017.05.068

Rugg MD, Vilberg KL. 2013. Brain networks underlying episodic memory retrieval. Curr Opin Neurobiol 23: 255-260. doi:10.1016/j.conb.2012.11 .005

Savalli G, Bashir ZI, Warburton EC. 2015. Regionally-selective requirement for D1/D5 dopaminergic neurotransmission in the medial prefrontal cortex in object-place associative recognition memory. Learn Mem 22: 69-73. doi:10.1101/lm.036921.114

Schlichting ML, Preston AR. 2015. Memory integration: neural mechanisms and implications for behaviour. Curr Opin Behav Sci 1: 1-8. doi:10.1016/j cobeha.2014.07.005

Scott H, Smith AE, Barker GR, Uney JB, Warburton EC. 2017. Contrasting roles for DNA methyltransferases and histone deacetylases in single-item and associative recognition memory. Neuroepigenetics 9: 1-9. doi:10.1016/j.nepig.2017.02.001

Siddiqui SA, Singh S, Ranjan V, Ugale R, Saha S, Prakash A. 2017. Enhanced histone acetylation in the infralimbic prefrontal cortex is associated with fear extinction. Cell Mol Neurobiol 37: 1287-1301. doi:10.1007/ s10571-017-0464-6

Silva AJ, Kogan JH, Frankland PW, Kida S. 1998. CREB and memory. Ann Rev Neurosci 21: 127-148. doi:10.1146/annurev.neuro.21.1.127

Staddon JER, Higa JJ. 1999. Time and memory: towards a pacemaker-free theory of interval timing. J Exp Anal Behav 71: 215-251.

St Jacques P, Rubin DC, Labar KS, Cabeza R. 2008. The short and long of it: neural correlates of temporal-order memory for autobiographical events. J Cog Neurosci 20: 1327-1341. doi:10.1162/ jocn.2008.20091

Vieira PA, Korzus E. 2015. CBP-dependent memory consolidation in the prefrontal cortex supports object-location learning. Hippocampus 25: 1532-1540. doi:10.1002/hipo.22473

Warburton EC, Glover CPJ, Massey PV, Wan H, Johnson B, Bienemann A, Deuschle U, Kew JNC, Aggleton JP, Bashir ZI, et al. 2005. CREB phosphorylation is necessary for perirhinal LTP and recognition memory. J Neurosci 25: 6296-6303. doi:10.1523/JNEUROSCI.0506-05 .2005

Weible AP, Rowland DC, Monaghan CK, Wolfgang NT, Kentrol CG. 2012. Neural correlates of long-term object memory in the mouse anterior cingulate cortex. J Neurosci 32: 5598-5608. doi:10.1523/JNEUROSCI $.5265-11.2012$

Zhang W, van Ast VA, Klumpers F, Roelofs K, Hermans EJ. 2018. Memory contextualization: the role of prefrontal cortex in functional integration across item and context representational regions. J Cogn Neurosci 30: 579-593. doi:10.1162/jocn_a_01218

Received May 23, 2019; accepted in revised form November 5, 2019. 


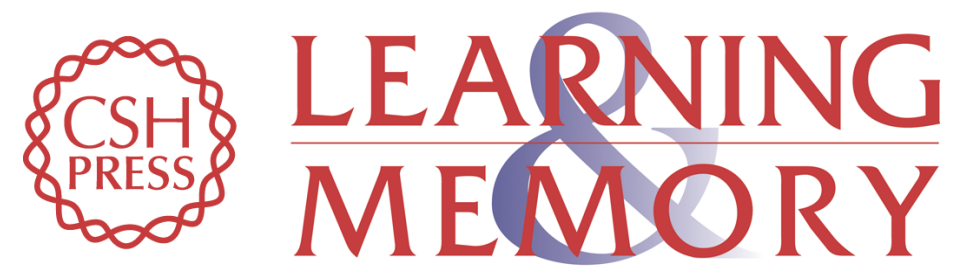

\title{
CREB transcription in the medial prefrontal cortex regulates the formation of long-term associative recognition memory
}

\author{
Gareth Robert Barker, Liang Fong Wong, James B. Uney, et al.
}

Learn. Mem. 2020, 27:

Access the most recent version at doi:10.1101/Im.050021.119

\begin{aligned} & \hline References $\begin{array}{l}\text { This article cites } 51 \text { articles, } 18 \text { of which can be accessed free at: } \\ \text { http://learnmem.cshlp.org/content/27/2/45.full.html\#ref-list-1 }\end{array} \\ & \begin{array}{c}\text { Creative } \\ \text { Commons } \\ \text { License }\end{array} \begin{array}{l}\text { This article is distributed exclusively by Cold Spring Harbor Laboratory Press for the } \\ \text { first } 12 \text { months after the full-issue publication date (see } \\ \text { http://learnmem.cshlp.org/site/misc/terms.xhtml). After } 12 \text { months, it is available under } \\ \text { a Creative Commons License (Attribution-NonCommercial } 4.0 \text { International), as } \\ \text { described at http://creativecommons.org/licenses/by-nc/4.0/. } \\ \text { Receive free email alerts when new articles cite this article - sign up in the box at the } \\ \text { Service } \\ \text { top right corner of the article or click here. }\end{array} \\ &$\hline\end{aligned}

